\title{
Three Decades of Italian Comparative Advantages
}

\author{
Luca De Benedictis \\ Università di Macerata, Italy
}

\section{INTRODUCTION}

$\mathfrak{T}$ HE structure of Italian exports - its characteristics, its changes over time, its causes and implications in terms of income and growth, employment, and fragility with respect to domestic and international shocks - has been the issue around which at least three generations of Italian economists have discussed and disagreed over the last 30 years.

If one has to attribute to one single cause the origin of this multi-faceted debate, that very cause would be the perplexity associated with the evidence of Italy being, on the one hand, a large industrialised country, with per capita income comparable to the top high-income OECD members (World Bank, 2004) and, on the other hand, being characterised by an export composition where traditional low-skilled labour-intensive sectors (OECD, 2001; and Peneder, 2003) such as Textiles, Wearing Apparel, Leather Products, Furniture and Footwear still play a relevant role. This anomaly in the Italian trade structure with respect to one of its fellow members of the G7, and its high level of persistence, is what makes of Italy a case in the international trading system.

This paper describes the primary feature giving rise to this debate: the Italian export composition and its evolution over time. The analysis makes use of the revealed comparative advantage (RCA) index associated with the name of Bela Balassa and, through non-parametric statistical techniques, estimates the empirical

The author is very grateful to MIUR (PRIN PIE 2003) and JETRO for the financial support and to Giancarlo Spagnolo for his encouragement. Discussions with Matteo Bugamelli, Giuliano Conti, Davide Castellani, Sergio de Nardis, Paolo Guerrieri, Fabrizio Onida and Lucia Tajoli are gratefully acknowledged. The author thanks Riccardo Faini for sharing his work on the topic and Lucia Piscitello for making her districts taxonomy available. He also benefited from the comments of two anonymous referees that largely influenced the restructuring of the paper. Many of the arguments of this paper come from the inspiring discussions the author had over the years with Massimo Tamberi. All remaining errors and omissions are the author's own responsibility. The data sets and the Rscript used in the paper can be downloaded from the webpage http://www.economiamc.org/ debenedictis. 
distribution of the Balassa index and tracks its dynamics during the last three decades of the twentieth century, from the 1970s to the present. The persistence in the pattern of RCA is then examined at the sectoral level using provincial data, controlling for the presence of industrial districts - characterised by a cluster of small family firms, a network of information-sharing and participation in innovation, Marshallian externalities and other strong agglomeration incentives - as the organisational form of firms.

The main results of the analysis are that the structure of Italian RCA is indeed highly persistent but is changing, and several sectors characterised by comparative disadvantage in the 1980s now show a comparative advantage; the distribution of Italian RCA changes sharply when it is examined at a macro-regional level, showing that regional disparities influence the shape of density function of national RCA; the sectoral composition of exports - when it is examined at a high level of sectoral disaggregation - is not so similar to one of the new industrialised countries (NICs) exporting labour-intensive goods, as one would $a$ priori expect. Finally, simple visual inspection of sectoral export data disaggregated at the provincial level and a Galtonian regression with an interacting dummy variable show that the persistence in the pattern of RCA appears to be positively related to the presence of industrial districts.

Even if the analysis applies to Italian data, the technique used in the paper can be easily replicated and applied to the study of the evolution of RCA of any other possible geographical entity, at the country, region or urban level.

The structure of the paper is as follows. Section 2 contains a short review of the debate on the Italian trade anomaly. Section 3 describes and discusses the characteristics of the Balassa index of RCA, and in Section $3 a$ the bounded version of the index is used to compare Italian RCA to several industrialised countries. In Sections $3 b$ and $3 c$ the persistence of Italian product specialisation through a scatter plot is visualised and the characteristics of Italian overall specialisation through the estimated density function of RCA are examined. In Section $3 d$ Italian RCA is compared with one of a selection of NICs. Section 4 extends the analysis to provincial data comparing, in section $4 a$, national RCA with one of four Italian macro-areas, and then, in Section $4 b$, the persistence in the Italian structure of comparative advantages is related with the diffuse presence of industrial districts in provinces highly specialised in sectors at the core of the Italian structure of RCA. Section 5 concludes.

\section{THE ITALIAN TRADE ANOMALY AND ITS CONSEQUENCES: A DEBATE OF LONG STANDING IN A NUTSHELL}

Why is a largely industrialised country, like Italy, exporting traditional lowskilled labour-intensive goods? From a pure trade theoretical point of view this is 
a puzzling anomaly. ${ }^{1}$ Seeking for a possible answer, one can rely on at least three main potential explanations of the actual structure of Italian comparative advantages: (a) the factor proportion theory of comparative advantages, associated with the predictions of the Heckscher-Ohlin theorem; (b) the theory of dynamic scale economies, Marshallian externalities, and agglomeration, related both to the new economic geography and to the literature on industrial districts; and (c) the theory of vertical differentiation and quality ladders. Even if these three approaches are perfectly compatible with each other, it is better to keep them separated, in order to highlight the key elements of each specific approach.

Starting from factor proportion, the Heckscher-Ohlin theorem predicts that Italy would specialise in traditional sectors - producing and exporting labourintensive goods - if the country is a labour-abundant country. But, is Italy a labour-abundant country? A positive answer would be empirically supported only for periods before the second half of the twentieth century (Graziani, 1989). Since the mid-1950s, Italy began a process of capital accumulation which brought the country almost to the same average level of capital-labour ratio as other large industrialised countries. Since then, according to the Heckscher-Ohlin theorem, Italy should export capital-intensive goods to the rest of the world. Why is the degree of persistence of the Italian exports' structure so high, in spite of the substantial change in factor endowments? Why is Italy still exporting what it was exporting in the 1950s?

De Benedictis and Padoan (1999) and Epifani (1999) both offer different but converging interpretations of the persistence of the Italian structure of comparative advantages; both emphasise the role played by dynamic economies of scale in making the Italian export composition sticky (Krugman, 1987). Both show how, in a Ricardian framework (De Benedictis and Padoan, 1999) or in a Heckscher-Ohlin framework (Epifani, 1999), with dynamic economies of scale the country will become more and more efficient in the production of the goods it was initially exporting, so that the dynamics of productivity would lock-in the country to its initial comparative advantage. If learning-by-doing is quite effective it can nullify the effect of a change in factor proportions on comparative

\footnotetext{
${ }^{1}$ Aside from trade theory, very many different explanations have been put forward by the numerous social scientists that have discussed the issue over the years (Graziani, 1989; and Ginsborg, 1989). The most acquainted are the heritage of national economic history (Rossi and Toniolo, 1996) and the dualistic structure of the economy (Lutz, 1962), the role of family-owned firms (Burkart, Panunzi and Shleifer, 2002), the inefficiencies of both private and publicly owned large firms (De Cecco, 2004), the large share of small firms in the size distribution of firms (Pagano and Schivardi, 2003), the underdevelopment of the financial system and the inefficiency of the legal system (Guiso, Sapienza and Zingales, 2005), the prevalence of the rentier over the innovator (Nardozzi, 2004), and the absence of industrial policy and the reliance on the strategic use of the exchange rate to enhance competitiveness (Guerrieri and Rossi, 2000). All these various features of Italian development reinforce the traditional structure of comparative advantages emerging in the 1950s.
} 
advantages and the export structure would remain unchanged. If this is the case, Italy is still exporting traditional low-skilled labour-intensive goods not because it is a labour-abundant country but because it was a labour-abundant country. But, why is Italy characterised by such a high degree of learning-by-doing? The most acquainted answer is the diffusion in the late 1950s of industrial districts (Becattini, 1999; and IPI, 2002) that allowed small firms to exploit dynamic scale economies due to Marshallian externalities. Without such intensive clustering, small family firms would not have been able to increase productivity and to horizontally and vertically differentiate their production.

From the 1970s onwards, the Italian anomaly of an industrialised country characterised by the predominance of clusters of small firms producing and exporting traditional goods generates an anti-cyclical debate on the consequences for a small open country to rely on an export-led growth strategy, while exporting low-skilled labour-intensive goods. ${ }^{2}$ On the con side of the debate Conti (1978), Onida (1978), Modiano (1982) and Guerrieri and Rossi (2000), among many others, noticed that the characteristics of Italian exports composition had strong implications in terms of national dependence on imported technology, a low rate of $R \& D$ investment, a limited incentive for small firms to grow in size, and an intrinsic weakness of the export-led strategy, associated to the low-income elasticity of Italian exports. Iapadre (1996) and de Nardis (1997) put the accent on the relatively high rigidity of the Italian export structure and on the possible risks in terms of sluggish growth rate, low employment capacity, and fragility with respect to exogenous shocks, such as the EMU or a drop in world demand, associated to it. On the pro side Becattini (1989 and 1999), Brusco and Paba (1997), and many others, highlighted the qualities of a social and economic structure self-organised as a Marshallian district, and Signorini (2000) shows strong and robust evidence of the efficiency of small firms clustered into local industrial districts. Finally, Faini (2004) takes an equidistant position, noticing that no empirical evidence supports the view of the Italian pattern of specialisation being responsible for the declining export performance and, in general, for the economic difficulties of the country.

Nowadays, Italy is growing at an average rate of 1.5 per cent yearly - half a point below the EU average rate - and that total factor productivity has decreased in the second half of the 1990s, while it accelerated in the US and in the OECD countries, on average, the anti-cyclical debate on the Italian anomaly has gained momentum again.

Among the various reasons that have been put forward to explain why the Italian sectoral specialisation is now facing more severe limits than before (see

${ }^{2}$ One might go even further back in history, all the way to the end of the Roman Empire or to the Venetian crisis of the seventeenth century (Glamann, 1974; and Rossi and Toniolo, 1996) to find examples of similar arguments on the role of the exports crisis on the decline of the State. 
FIGURE 1

The Italian Anomaly: 1980s vs 1990s

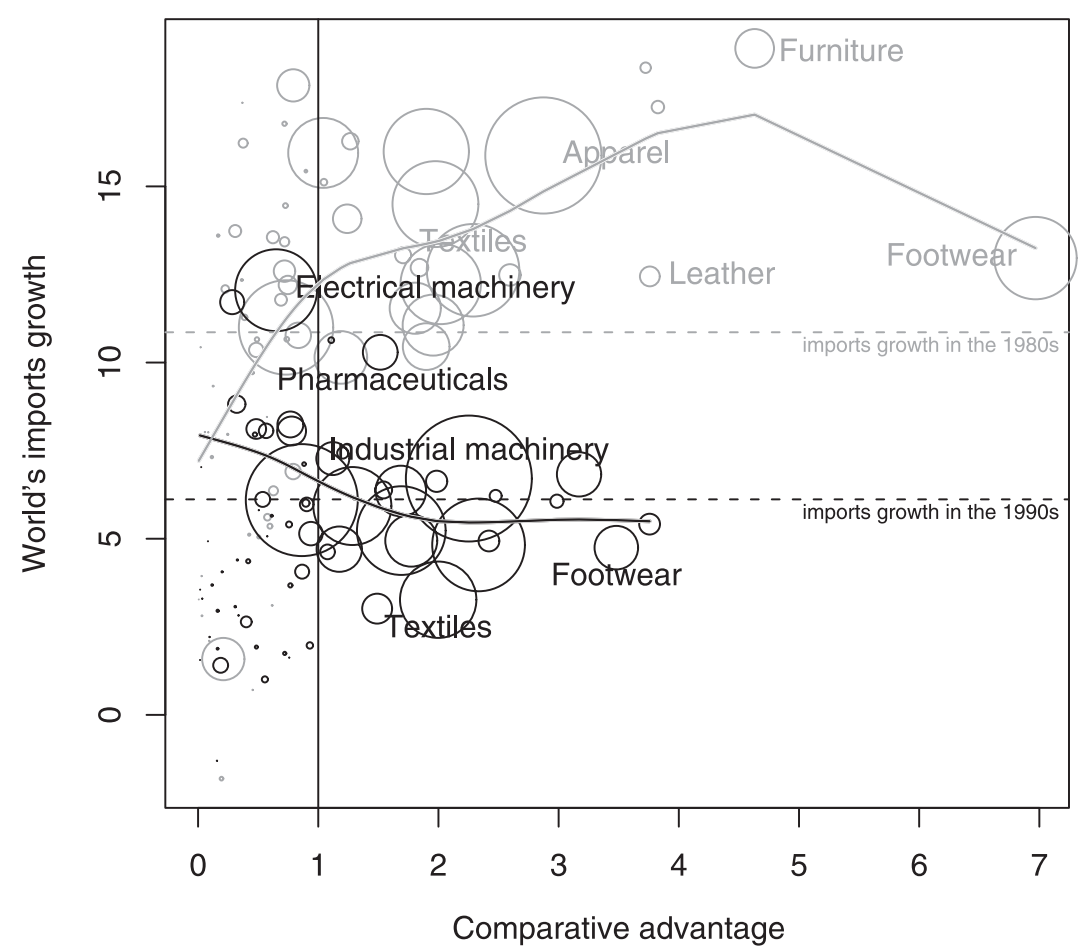

Onida, 1999, for an extensive review of the issue) the most common one is the fiercer competition from the NICs, associated to an overvalued euro. A cause less thought about is the change in the characteristics of the sectoral world's demand.

Figure 1 plots the rate of growth of the sectoral world's imports against the Balassa index of Italian sectoral comparative advantages, the index that is used throughout the analysis and that will be more properly defined in Section 3. Each sector is identified by a circle whose size is proportional to the share of the same sectoral exports in total Italian exports; lighter circles correspond to the average values in the 1980s, while black circles correspond to the average values in the 1990s. The vertical line separates sectors characterised by comparative advantage (the ones with an index taking a value greater than one) from sectors with comparative disadvantages. The two horizontal lines identify the average rate of growth of the world's demand for sectoral imports in the 1980s (the lighter dotted line) and in the 1990s (the darker dotted line). Sectors above the horizontal line show a rate of growth of world's demand higher than the average. The curves are non-parametrically fitted regression functions, weighted by the sectoral share in total Italian exports. 
The Italian anomaly is immediately evident. The sectors with higher comparative advantages, both in the 1980s and in the 1990s, are traditional low-skilled manufactures (Footwear, Furniture, Leather, Apparel and Textiles) and their share in total exports is quite remarkable. In the 1980s, the world's demand for products belonging to these sectors was growing faster than the sectoral average. In the 1990s, characterised by a drop in the world's demand for imports, the same sectors became relatively less internationally demanded, being substituted by Electrical Machinery, Pharmaceuticals and Industrial Machinery. As the nonparametric curves show, the slope of the sectoral world's demand with respect to Italian RCA has changed sign from the 1980s to the 1990s. The relationship switched from being largely positive to negative or insignificant, implying that Italy's product specialisation is in sectors now less internationally demanded.

In the next section the details of both Italy's product specialisation (Schott, 2004) and overall specialisation (De Benedictis and Tamberi, 2004) will be listed, focusing both on the role of single sectors, and on the shape of the distribution of RCA. In order to describe how the structure of Italian exports has evolved over time, product specialisation using a traditional measure of revealed comparative advantages will be quantified. The goal will be to measure Italian RCA, to emphasise the role of single sectors, to estimate the distribution of RCA and its persistence, and to compare it with the one of a group of OECD and NICs.

\section{ITALIAN REVEALED COMPARATIVE ADVANTAGES}

Among the metrics used in the analysis of bilateral and multilateral trade flows, the first and still most widely used measure ${ }^{3}$ built on one single variable is the Balassa (1965) index of revealed comparative advantage (RCA). ${ }^{4}$

\footnotetext{
${ }^{3}$ The literature on the appropriateness of different measures of comparative advantage and on their theoretical interpretation is wide. More discussion on the topic can be found in Bowen (1983), Ballance, Forstner and Murray (1987), Vollrath (1991) and Lafay (1992). See also Iapadre (2001), Laursen (2002, Ch. 3) and OECD (2005) for a general discussion on the various measures used in the literature.

${ }^{4}$ The use of the Balassa index has its own advantages and disadvantages. It is easy to construct, its interpretation is intuitive (see the Appendix for a simple application and De Benedictis and Tamberi, 2004, for a more analytic explanation), and it is largely used (see Yi, 2003, for a recent application) in very different contexts and applied to different variables, such as employment, value added, productions, patents (see Kim, 1995, for an application of the index to US regional employment). On the other hand, many authors have identified some shortcomings inherent in the index (Bowen, 1983; and Yeats, 1985) and the link between the index and the theory of comparative advantages is problematic (Vollrath, 1991). Several alternatives are possible, the most commonly used in the analysis of comparative advantages are the ones based on both export and import flows (i.e. the normalised trade balance). The use of those measure is not advisable when the analysis is structured on a regional basis. Import marketing locations rarely coincide with the regional locations where imported goods are sold, and the information contained in imports data can be misleading.
} 
The traditional way of defining the Balassa index - which is indicated as $b$ - is:

$$
b_{i j t}=\frac{X_{i j t} / X_{w j t}}{X_{i t} / X_{w t}}
$$

where - for every time period $t$ considered $-i$ denotes a specific country, $w$ indicates the world economy (i.e. the entire set of countries considered in the analysis), and $j$ is a specific sector. $b$ is, therefore, a sectoral relative export measure in terms of share of world exports. Since the numerator ranges from 0 (the country is not exporting products belonging to that particular sector) to 1 (the country is an international monopolist in such category of products), and the denominator $\left(\frac{1}{d}=\frac{X_{i t}}{X_{w t}}\right)$ - which is the economic dimension of the country, in export terms - also ranges from 0 to 1 , then $b$ ranges between 0 and $d$. Therefore, equation (1) - omitting subscripts - can be written as:

$$
b=c \cdot d,
$$

where $c$ is the sectoral market share of country $i$ in sector $j$, and $d$ is the time variant upper bound of $b$ (common to all sectors $j$ ). From equation (2) we can say that when $b \in[0,1)$ (which is equivalent to saying that $c<1 / d$ ) the country has a comparative disadvantage in sector $j$; while it has a comparative advantage in sector $j$ if $b \in(1, d]$ (when $c>1 / d$ ). The demarcation value is given by the condition $c=1 / d$, corresponding to the case where the country displays a sectoral market share equal to its total share of world exports.

For every country, the distribution of $b$ is characterised by a fixed lower bound $(0)$, a time variant upper bound (d), and an invariant demarcation value (1). De Benedictis and Tamberi (2004) give a detailed description of the characteristics of the distribution of $b$. For the current argument, the main feature of the distribution is that its shape is asymmetric (as can be seen from the decentred position of the demarcation line in Figure 1, where $b$ is used as the metric of the horizontal axis), and that the degree of right skewness is inversely related to the country's share of total world exports, $1 / d$ (i.e. small countries tend to be characterised by high maximum levels of sectoral $b$ 's).

In order to sharply reduce the degree of asymmetry of the distribution, the index can be made bounded using the transformation: ${ }^{5}$

$$
b^{B}=\frac{(b-1)}{(b+1)} .
$$


The $b^{B}$ version of $b$-where the superscript $B$ stands for bounded - ranges between $[-1,1]$, and its demarcation value is at 0 . The above transformation is useful for visual purposes, giving emphasis both to comparative advantaged and comparative disadvantaged sectors, so we will use it throughout the analysis. Even if moving from $b$ to $b^{B}$ leaves the rank-order of sectors invariant, the interpretation of the numerical value of $b^{B}$ is less evident, so we will present the original $b$-values in the Appendix.

\section{a. Italian RCA in the 1970s and in the 1990s: An International Comparison}

In this section $b^{B}$ is used to analyse the Italian product specialisation together with the one of five other OECD countries, for comparison. In Figure 2, six scatter plots have been collected for Italy, Spain, Japan, Germany, the US and the UK in order to compare trade structures and trade patterns internationally. Let us take the first plot on the upper left (Italy) as illustrative; the discussion extends with the other five plots for analogy.

On the horizontal axis we have the sectoral $b^{B}$ values for 1970 , and on the vertical axis we have the corresponding $b^{B}$ values for $1998 .{ }^{6}$ The two lines drawn in correspondence of the demarcation value $b^{B}=0$ separate sectors with revealed comparative disadvantage from sectors with revealed comparative advantage, and define four quadrants. The two quadrants along the main diagonal contain sectors that modified their relative position, from comparative disadvantage to comparative advantage (upper quadrant to the left) or vice versa (lower quadrant to the right). The two quadrants along the secondary diagonal contain sectors that did not modify their position in terms of comparative advantage (upper quadrant to the right) or comparative disadvantage (lower quadrant to the left). Relative changes are evident inside each one of the four quadrants. The $45^{\circ}$ dotted line visualises a condition of pure persistence. ${ }^{7}$

The data used in Figure 2 is collected by the OECD (2002), at the two-digit level of the SITC (rev. 2) classification (see the Appendix for a description of the

\footnotetext{
${ }^{5}$ For a discussion of the advantages of this transformation see Laursen (2002) and Iapadre (2001). See also Brasili, Epifani and Helg (2000) and Mancusi (2001) for applications of the same transformation to export and patent data, and Vollrath (1991) for an alternative log-transformation. A critical discussion of the various possible transformations is in De Benedictis and Tamberi (2001).

${ }^{6}$ The choice of the two years 1970 and 1998 - that correspond to the initial and the final year of the time series - does not influence the results. The robustness of the analysis was verified to the choice of initial and final years, using 1971 and 1997 as alternatives. The exercise was also replicated using five-year averages, but the effect was not remarkable.

${ }^{7}$ It is called pure persistence since it implies not only that Italy has not changed its structure of RCA, but that also all other countries considered did not change their structure.
} 
FIGURE 2

Comparative Advantage (1970-1998): Italy, Spain, Japan, Germany, USA, UK

Italy

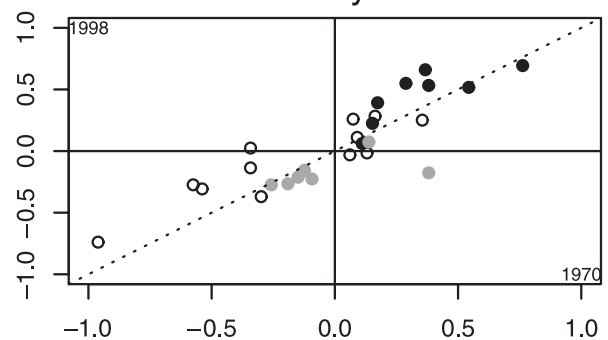

Japan

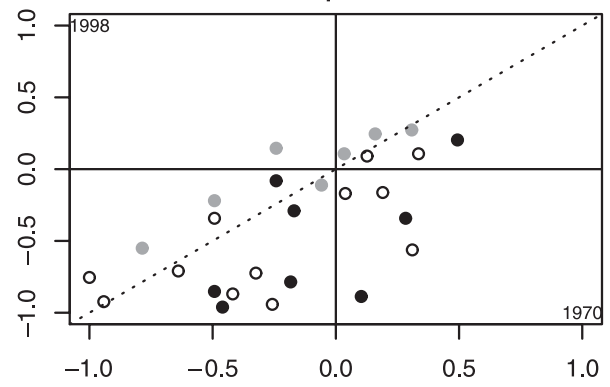

USA

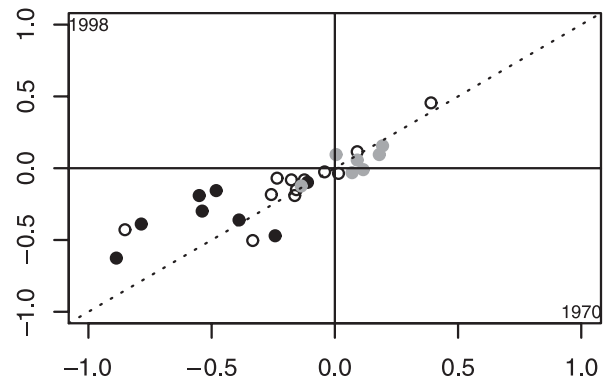

Spain
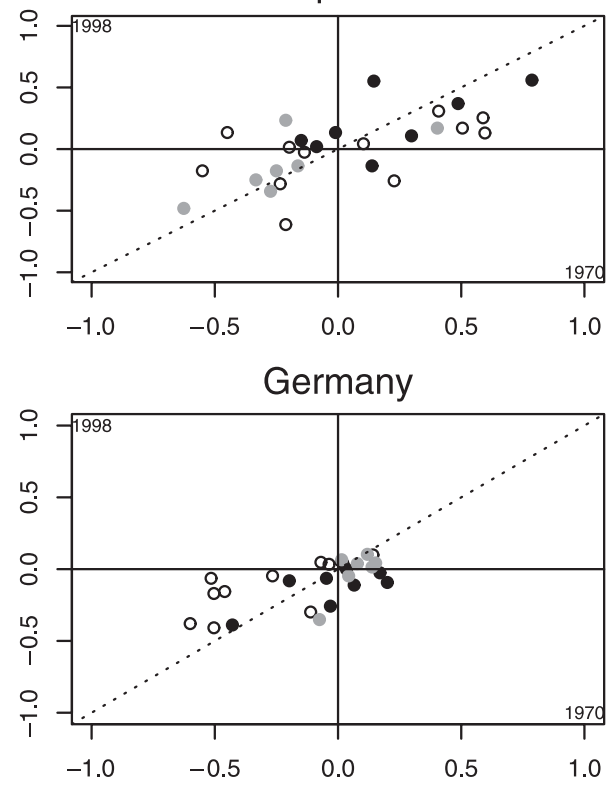

UK

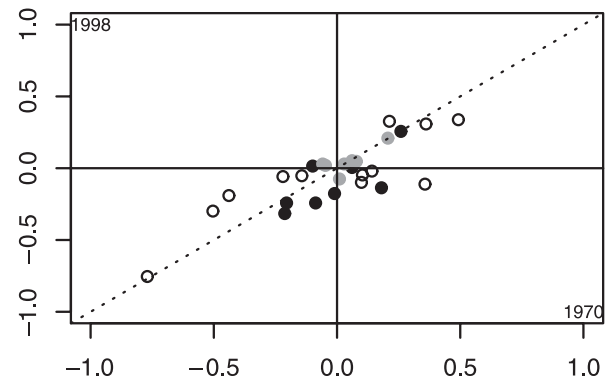

Note:

(•) 'Traditional sectors'; (॰) 'advanced sectors' and (०) 'other'.

Data Source: OECD, STAN database, 2002.

data); the sectors included are 27 manufacturing sectors, that we have roughly divided into 'traditional sectors', 'advanced sectors' and 'other', ${ }^{8}$ respectively indicated in Figure 2 by the symbols $(\bullet),(\bullet)$ and (०).

\footnotetext{
8 The classification is related to the OECD's 'high-tech', 'low-tech' taxonomy, discussed in Peneder (2003). See column 1 of Table A1 in the Appendix for the correspondence among sectors and the taxonomy's classes.
} 
The information content of Figure 2 is largely self-explanatory. ${ }^{9}$ Starting from Italy it is evident that it had, and still has, very strong RCA in "traditional sectors' such as Textiles, Wearing Apparel, Leather, Footwear, Furniture, and Pottery and China, it has improved its RCA in many 'traditional sectors' (which lie above the $45^{\circ}$ dotted line) but not in the top ones (Footwear, and Wearing Apparel), and it has also improved its RCA in some 'other sectors' such as Machinery and Other Manufacturing. What is also remarkable is the persistence in the structure of comparative advantages: almost all sectors are in the two quadrants along the secondary diagonal. The only other country that shows such a high persistence (a low dispersion around the $45^{\circ}$ line) is the US.

The opposite case is represented by Spain. From the 1970s to the 1990s Spain changed markedly its pattern of comparative advantages. Many sectors with a positive $b^{B}$ - 'traditional sectors' but not only - lie below the $45^{\circ}$ line (with the noteworthy exception of Non-metallic Products), while some sectors - both 'traditional sectors' and 'advanced sectors' - moved from being comparative disadvantaged to be comparative advantaged. Spain, which for many reasons can be considered similar to Italy, followed, during the period considered, a very different product specialisation path.

On the other hand, Japan and Germany are somehow similar cases. Both have in common an export structure characterised by a limited number of sectors with comparative advantages - both 'advanced sectors' (Non-electrical Machinery, Transport Equipment, and Professional Goods) and 'other sectors' (Rubber Products); in both cases a conspicuous number of sectors moved from a positive $b^{B}$ value to a negative one; both countries are characterised by a high dispersion around the $45^{\circ}$ line.

The US follows a fairly stable path. The large majority of sectors lie close to the $45^{\circ}$ line; as for Japan and Germany the value of the $b^{B}$ 's is quite small with only one exception being Tobacco, with a $b^{B}$ around 0.5 ; finally, the sectors characterised by RCA are mainly 'advanced sectors'.

As for the US, the UK follows a fairly stable path, with the peculiarity of a relevant number of 'traditional' and 'other sectors' - such as Leather and Products, Footwear, Tobacco, Rubber Products, Non-ferrous Metals, Metal Products, and Transport Equipment - losing their original comparative advantage.

This bird's-eye view of RCA in six industrialised countries gives evidence to the Italian product specialisation anomaly and to the persistence of the phenomenon. At the same time it offers two relevant insights. On the one hand, what is evident in Figure 2 is that the Italian top $R C A$ 'traditional sectors', such as Footwear and Wearing Apparel, decreased their $b^{B}$ values from 1970 to 1998,

${ }^{9}$ Both the choice of the level of sectoral disaggregation and the specific clustering is due to expositional and visual purposes. 
while 'other sectors', such as Machinery, have increased their $b^{B}$ values. Nowadays, the Italian product specialisation is therefore characterised by an overall reduction in relevance to 'traditional sectors', by a reproportion of relative weights inside the category (more textiles and leather, less apparel and footwear), and by the emergence of metallic and non-metallic products, machineries mainly used in the production of traditional products. On the other hand, the relatively high level of persistence in the structure of RCA is not a specific feature of Italian product specialisation but is common to other counties as well, i.e. the US. We will come back to both issues later on.

\section{b. Persistence and Change}

In order to properly verify that the persistence of the Italian structure of comparative advantages is not limited to across-product specialisation but extends also to within-product specialisation, ${ }^{10}$ we have to switch to a different international data set, that should make it possible to define the $b^{B}$ values at the higher possible disaggregation.

The data set chosen is the UN-World Bank (1999) data set, including COMTRADE data on 193 exporting countries, with a sectoral disaggregation that, at four digits of the SITC (rev. 2) classification, includes 540 manufacturing sectors (see the Appendix for a description of the data set). From such data set one obtains very detailed information on sectoral RCA at the cost of losing insights on the first decade of our previous analysis, since the UN data set covers a time span of just 13 years, from 1986 to 1998.

In Figure 3 we replicated the Italian scatter contained in Figure 2 using the UN-World Bank data set. The years considered are 1986 and 1998. Since also with these data the distribution of the $b$ 's showed a strong right skewness we transformed $b$ 's in $b^{B}$ 's, so as to give emphasis both to comparative advantages $\left(b^{B}>0\right)$ and disadvantages $\left(b^{B}<0\right)$. We superimposed to the plot the continuous OLS regression line of $b_{1998}^{B}$ on $b_{1986}^{B}$.

In Figure 3, the large majority of sectors are still located in the two quadrants along the secondary diagonal, containing sectors that did not modify their relative condition in terms of comparative advantage (190 sectors; 35 per cent of total sectors considered) or disadvantage ( 250 sectors; 49 per cent). Among the 190 sectors in the upper left quadrant of Figure 3, 60 per cent of them (115 sectors) lie above the $45^{\circ}$ line, indicating an increase in $b^{B}$, and what is also worth noticing is that sectors with revealed comparative disadvantage are much more dispersed around the $45^{\circ}$ line than sectors with comparative advantages.

\footnotetext{
${ }^{10}$ A movement along the quality ladder would result in no change at all in across-product specialisation, being hidden by its intra-product nature.
} 
FIGURE 3

Persistence of Italian Comparative Advantages (1986-1998)

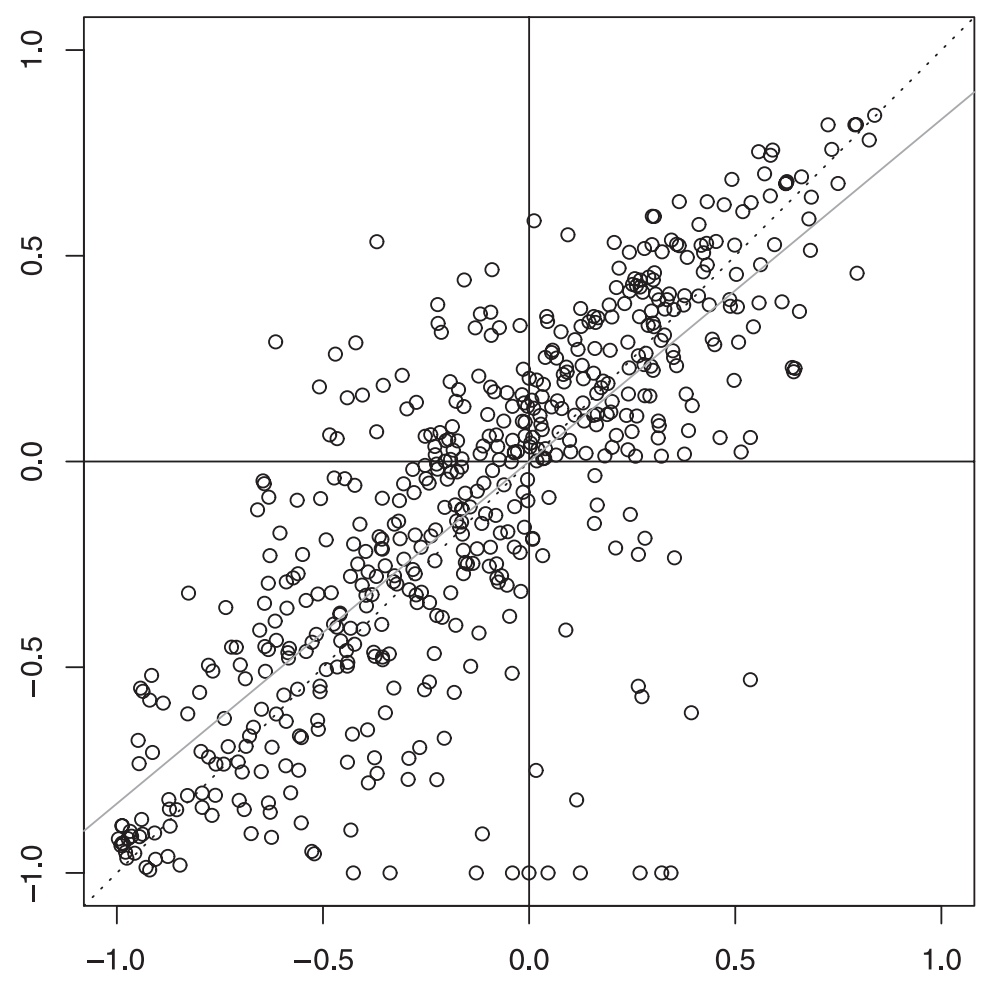

Note:

The dotted line is the pure persistence $45^{\circ}$ line; the continuous line is the OLS regression: $b_{1986}^{B}=0.001+0.83 \cdot b_{1998}^{B}$.

Data Source: UN-World Bank database, 1999.

The most noticeable fact emerging from Figure 3 - and unobservable in highly aggregated data - is that many sectors that were comparatively disadvantaged in 1986 became comparatively advantaged in 1998 (66 sectors, 12 per cent), moving from the lower quadrant along the secondary diagonal to the upper quadrant along the main diagonal. An evidence obviously in contrast with the presumption of a never changing pattern of RCA. Table 1 lists examples of the sectors moving from $b^{B}<0$ to $b^{B}>0$, and vice versa.

Finally, the degree of persistence of the Italian structure of comparative advantages $^{11}$ is anyway remarkable, even when using higher disaggregated data as in

${ }^{11}$ De Nardis (1997) measured the persistence of the Italian RCA testing the AR(1) characteristic of the various sectoral time series, finding very different autoregressive structures. 
TABLE 1

Our Elaborations on UN-World Bank, TradeCAN Database, 1999

\begin{tabular}{llrr}
\hline SITC & Sector & $b_{1989}^{B}$ & $b_{1998}^{B}$ \\
Code & & & \\
\hline 7841 & Chassis fitted with engines, for motor vehicles & -0.369 & 0.534 \\
7851 & Motorcycles, auto-cycles and cycles fitted with motor & -0.090 & 0.466 \\
6424 & Paper and paperboard, cut to size or shape & -0.157 & 0.441 \\
6591 & Linoleum and similar floor coverings & -0.222 & 0.381 \\
8421 & Overcoats and other coats & -0.093 & 0.363 \\
6579 & Special products of textile materials & -0.118 & 0.358 \\
6750 & Hoop and strip, of iron or steel, hot and cold rolled & -0.221 & 0.336 \\
5147 & Carboxyamide-function compounds & -0.022 & 0.330 \\
6282 & Transmission, conveyor or elevator belts or belting & -0.072 & 0.325 \\
7421 & Reciprocating pumps & -0.131 & 0.325 \\
6130 & Furskins, tanned or dressed & -0.213 & 0.314 \\
5825 & Polyurethanes & -0.092 & 0.307 \\
7913 & Railway and tramway coaches, vans and trucks & -0.615 & 0.291 \\
8483 & Fur clothing (not including headgear) & -0.420 & 0.288 \\
6417 & Paper and paperboard, corrugated, creped, etc. & -0.470 & 0.261 \\
7757 & Electro-mechanical, domestic appliances & 0.160 & -0.034 \\
8922 & Newspapers, journals and periodicals & 0.048 & -0.087 \\
5123 & Phenols and phenol-alcohols & 0.165 & -0.106 \\
8462 & Under-garments, knitted or crocheted, of cotton & 0.245 & -0.129 \\
8991 & Articles and manufactures of carving or moulding material & 0.158 & -0.151 \\
8994 & Umbrellas, parasols, walking-sticks & 0.281 & -0.187 \\
5836 & Acrylic polymers, methacrylic polymers and acrylo-methacrylic & 0.009 & -0.187 \\
7112 & Auxiliary plant for use with boilers of heading & 0.008 & -0.189 \\
8429 & Other outer garments, men's and boys', of textile fabrics & 0.210 & -0.210 \\
6254 & Tyres, pneumatic, new, of a kind normally used on motorcycles & 0.265 & -0.226 \\
7243 & Sewing machines and furniture for sewing machines & 0.033 & -0.229 \\
6574 & Elastic fabrics and trimmings & 0.352 & -0.234 \\
8959 & Other office and stationery supplies & 0.089 & -0.410 \\
6551 & Knitted or crocheted fabrics, not elastic nor rubberised & 0.537 & -0.530 \\
5122 & Cyclic alcohols & 0.265 & -0.546 \\
7511 & Typewriters & 0.274 & -0.572 \\
\hline & & &
\end{tabular}

Figure 3. In the case of pure persistence the dotted $45^{\circ}$ line and the continuous line corresponding to the linear OLS would overlap, while they would be orthogonal in the case of complete structural change. In Figure 3 the two lines are very close to each other, implying a high degree of persistence, on average. The estimated $\beta$ is equal to 0.83 and is statistically significant and different from one. ${ }^{12}$ If $\hat{\beta}$ had been greater than one this would have meant that Italy would have become

${ }^{12}$ The null hypothesis of $\hat{\beta}=1$ was tested using an $F$-test similar to the Chow test but the null was not accepted. In order to take into account the possible influence of outliers we also performed a resistant regression (using a median absolute deviation estimator), but the difference was not noticeable. 
more specialised in products where it was already specialised in the 1980s (and less specialised in products characterised by negative $b_{1986}^{B}$ ). Since $\hat{\beta}$ is lower than one, the opposite tendency seems to be supported by the data: Italy is becoming less specialised in traditional sectors and new sectors are emerging.

We will look for support for this finding - indicating both high relative persistence and some remarkable change in the distribution of Italian RCA - estimating the density function of $b^{B}$ in 1986 and 1998 and testing for the significance of the change occurred.

\section{c. Estimating RCA Density}

In this section more emphasis is given to the ordinal content of the Balassa index of RCA, moving from the analysis of product specialisation to the one of overall specialisation. We will therefore study the shape and the dynamics of the overall structure of the Italian RCA, leaving aside the intra-distributional changes that have previously been observed. Using non-parametric statistics we will estimate the probability density function (PDF) of the Italian sectoral RCA. As for the scatter plot in Figure 3, given the skewness of the b's the analysis will be carried out using $b^{B}$ 's. A kernel density estimate will be used, ${ }^{13}$ adopting a Gaussian kernel function and a normal optimal smoothing parameter, as suggested by Silverman (1986) and Bowman and Azzalini (1997). Since the aim is to compare PDFs along time, the bandwidth of the PDF will be kept (the smoothing parameter) constant: we will estimate it for 1986 and will also apply it to 1998. The results are set out in Figure 4.

The vertical line in Figure 4 indicates the fixed demarcation value, $b^{B}=0$; if we take such value as a focal point, it can be observed that the distribution is bell-shaped but still skewed, even on the $b^{B}$ dimension, and that the density is higher around the demarcation value (in the interval $-0.5<b^{B}<0.5$ ).

Starting from 1986, the shape of the distribution is relatively centred and is characterised by high $b^{B}$ values in the right tail and by a noticeable bimodality. The principal mode is below the demarcation value, while the hump to the right of the distribution (around $b^{B}=0.2$ ) indicates that a conspicuous number of sectors were characterised by high $b^{B}$ values.

The estimated PDF shows a noteworthy evolution in 1998. The major change is that the overall distribution has moved to the right, with a small increase in the number of sectors with very low $b^{B}$ values and with a comprehensive increase in the number of sectors with $b^{B}$ values around the median. A further major change is that the secondary mode has switched position, moving from the left to the

${ }^{13}$ An intuitive explanation of the methodology applied to estimate the kernel densities is described in the Appendix. See Silverman (1986) for a review of the topic. 
FIGURE 4

Kernel Density of Italian RCA (1986-1998)

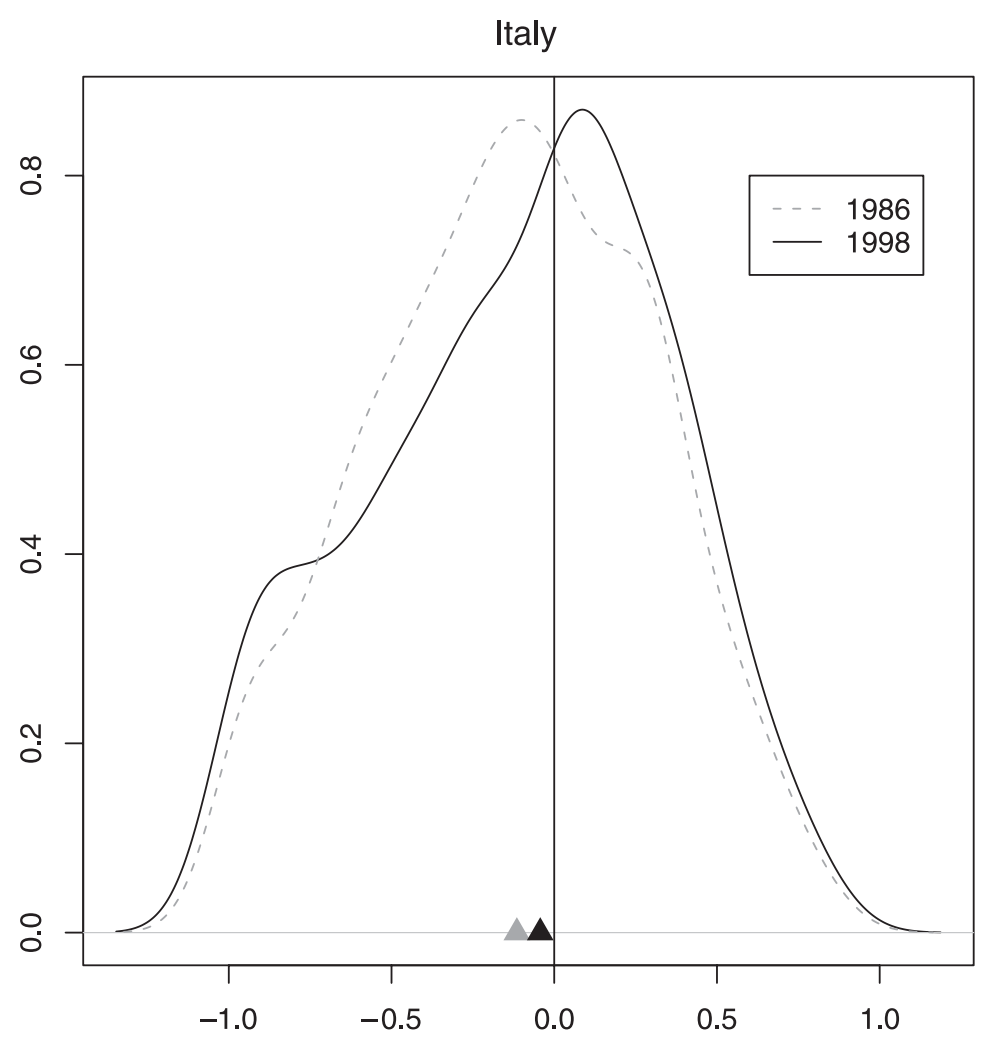

Note:

The vertical line is the demarcation value $b^{B}=0$; triangles indicate the location of the median in 1986 (light) and 1998 (black).

Data Source: UN-World Bank database, 1999.

right, with sectors following a pattern of convergence towards the two modes. Finally, the median itself has moved to the right and is now closer to the demarcation value. Almost 50 per cent of the Italian sectors show a revealed comparative advantage. ${ }^{14}$

The statistical significance of the change through a two-sample KolmogorovSmirnov test of stochastic dominance was tested. The null hypothesis that the distribution function of $b_{1986}^{B}$ is not greater than the distribution function of $b_{1998}^{B}$ was accepted with a $p$-value of 0.0275 , indicating a significant left shift in the position of the distribution.

${ }^{14}$ The value of the median is -0.115 for $b_{1986}^{B}$, and -0.043 for $b_{1998}^{B}$. 
Hence, in spite of the relative high persistence of the Italian structure of RCA the analysis of the density functions showed a significant degree of mobility. Did this have any influence in terms of similarity with the RCA structure of other countries? Can the influence of regional disparities on the national overall specialisation be explored? Each issue will be discussed in turn in the next two sections.

\section{d. Similarity: OECD Countries and the NICs}

Being highly specialised in traditional low-skilled labour-intensive sectors, Italy can be particularly sensitive to the growing relevance of Asian NICs in international markets. This increase in competition is frequently considered the problem that small Italian firms are already facing, and calls for protection against the unfair competition of labour-abundant countries are becoming popular in Italy. The starting point of these claims is that Italy's product specialisation is similar to those of the NICs and that they are competing on the same sectoral markets; the sharp reduction in Italian export shares is used as supporting evidence.

While the second piece of evidence is incontrovertible, the first one is less certain. Several authors (de Nardis and Traù, 1999; and De Benedictis and Tamberi, 2000) have already stressed that underestimating the role of vertical differentiation in analysing trade competition between Italy and the NICs can seriously misrepresent the intensity in competition. A common way to assert it is to verify the level of overlap in the structure of RCA. ${ }^{15}$ Table 2 contains the rank correlation of Italian RCA with a group of OECD countries and NICs, together with the autocorrelation of the same countries' RCA along time.

As far as Italy is concerned, its rank autocorrelation coefficient is 0.91 at a two-digit level and 0.80 at a four-digit level. It is the highest in the reduced sample used in Table 2. The coefficient is, however, not very far from one of the US (two-digit and four-digit levels) and, surprisingly, from the one of Japan ${ }^{16}$ (four-digit level). What seems, therefore, to be relevant is not persistence per se but persistence in a specific structure of RCA. In this case Italy is indeed an anomaly among the industrialised countries.

The Italian rank correlation with respect to the other countries considered shows a negative sign in the case of the OECD countries and a positive one in the case

\footnotetext{
${ }^{15}$ A possible alternative is to compare unit values of sectoral exports. See de Nardis and Traù (1999) and Amighini and Chiarlone (2004) for applications to Italian RCA.

${ }^{16}$ Japan is showing a high-rank autocorrelation coefficient at the two-digit level and a much lower coefficient at the four-digit level. In the former case, the high persistence in rank indicates that changes occurred within product groups and in a fairly ordered way (with reference to Figure 2, the product specialisation is changing but the order of relevance of the sectors remains relatively unchanged).
} 
TABLE 2

Our Elaborations on UN-World Bank TradeCAN Database, 2003

\begin{tabular}{|c|c|c|c|c|c|}
\hline \multirow[t]{2}{*}{ Country } & \multirow[t]{2}{*}{ Year } & \multicolumn{2}{|c|}{ Rank Correlation with Italy } & \multicolumn{2}{|c|}{ Rank Autocorrelation } \\
\hline & & $\begin{array}{l}\text { Two Digits } \\
\text { (35 sectors) }\end{array}$ & $\begin{array}{l}\text { Four Digits } \\
\text { (530 sectors) }\end{array}$ & $\begin{array}{l}\text { Two Digits } \\
(35 \text { sectors })\end{array}$ & $\begin{array}{l}\text { Four Digits } \\
\text { (530 sectors) }\end{array}$ \\
\hline \multirow[t]{2}{*}{ Japan } & 1986 & -0.24 & 0.00 & \multirow[t]{2}{*}{0.96} & \multirow[t]{2}{*}{0.78} \\
\hline & 1998 & -0.16 & 0.00 & & \\
\hline \multirow[t]{2}{*}{ USA } & 1986 & -0.53 & -0.20 & \multirow[t]{2}{*}{0.90} & \multirow[t]{2}{*}{0.79} \\
\hline & 1998 & -0.60 & -0.15 & & \\
\hline \multirow[t]{2}{*}{ UK } & 1986 & -0.13 & -0.02 & \multirow[t]{2}{*}{0.66} & \multirow[t]{2}{*}{0.72} \\
\hline & 1998 & -0.04 & -0.18 & & \\
\hline \multirow[t]{2}{*}{ Taiwan } & 1986 & 0.62 & 0.32 & \multirow[t]{2}{*}{0.67} & \multirow[t]{2}{*}{0.75} \\
\hline & 1998 & 0.48 & 0.27 & & \\
\hline \multirow[t]{2}{*}{ Thailand } & 1986 & 0.57 & 0.23 & \multirow[t]{2}{*}{0.76} & \multirow[t]{2}{*}{0.67} \\
\hline & 1998 & 0.46 & 0.19 & & \\
\hline \multirow[t]{2}{*}{ Romania } & 1986 & 0.28 & 0.22 & \multirow[t]{2}{*}{0.83} & \multirow[t]{2}{*}{0.68} \\
\hline & 1998 & 0.34 & 0.20 & & \\
\hline \multirow[t]{2}{*}{ Italy } & 1986 & 1.00 & 1.00 & \multirow[t]{2}{*}{0.91} & \multirow[t]{2}{*}{0.80} \\
\hline & 1998 & 1.00 & 1.00 & & \\
\hline
\end{tabular}

Note:

The table is a partial modification of Tables 3 and 4 in De Benedictis and Tamberi (2000).

of the NICs, at a two-digit level. With the exceptions of Romania and the US, ${ }^{17}$ the coefficient shrinks along time. Things are different at the four-digit level: both the degree of similarity with the NICs and of dissimilarity with the OECD countries is reduced, indicating an imperfect overlap in product specialisation.

The evidence that Italy is definitely competing with the NICs on the same product segments is therefore mixed, at the aggregate level, and the changes in the rank correlation coefficients indicate that vertical differentiation is taking place in traditional sectors. Italy is therefore not so similar to the NICs, as one would expect. Hence, this imperfect overlap in product specialisation could explain the ability of small Italian firms to still compete with firms located in labour-abundant countries.

\section{REGIONAL RCA}

The analysis on the structure and the dynamics of RCA can be extended from a national to a regional level. In spite of the contribution of Bertil Ohlin, until

\footnotetext{
${ }^{17}$ The tendencies have to do with the characteristics of the catching-up process with the technological leadership of the US and with the increased OPT flows between Italy and Romania that changed noteworthy the product specialisation of Romania after 1989.
} 
recently trade economists generally considered the national product specialisation as if the country - a country whatsoever - would have been a homogeneous economic entity. Often that is not the case, and as it is argued by the so-called New Economic Geography, the occurrence of trade flows and the changes in comparative advantages can be hardly understood without a theory of the location of economic activities in a dishomogeneous spatial dimension. As for Italy, this is certainly the case. Economic disparity among Italian regions is a well-known fact (Graziani, 1989; and Rossi and Toniolo, 1996). A less studied implication of that very disparity is whether it has had any impact on the dynamics of RCA at the national level. Is the Italian pattern of RCA dominated by the influence exerted by the changes in RCA which occurred in a particular geographic area? In order to address this question we have to consider export flows and RCA indices at a disaggregation; data is chosen at the provincial level.

Let us define the sectoral export share of each province relative to the world sectoral export share as:

$$
\Theta_{i j p}=\frac{X_{i j p} / X_{w j}}{X_{i p} / X_{w}},
$$

where the subscript $p$ stands for 'province'. On the other hand, the sectoral export share of each province relative to the national sectoral export share is:

$$
\theta_{i j p}=\frac{X_{i j p} / X_{i j}}{X_{i p} / X_{i}}
$$

We can now redefine, omitting subscripts, the RCA index described in equation (2) as:

$$
\Theta \equiv \theta \cdot b \equiv \theta \cdot c \cdot d,
$$

showing that the sectoral RCA of each province $(\Theta)$ is positively related to the national RCA index $(b)$ and to the sectoral export share of each province and negatively related to the national sectoral export share (inversely related to $\theta$ ).

From the identity 4 we can also derive the following expression:

$$
b \equiv \sum_{p} \Theta \cdot \frac{X_{i p}}{X_{i}},
$$

which indicates that the national sectoral RCA index is the weighted sum of the sectoral RCA of each province. Since the distribution of $\Theta$ is even more skewed 
FIGURE 5

The Italian Regional Anomaly

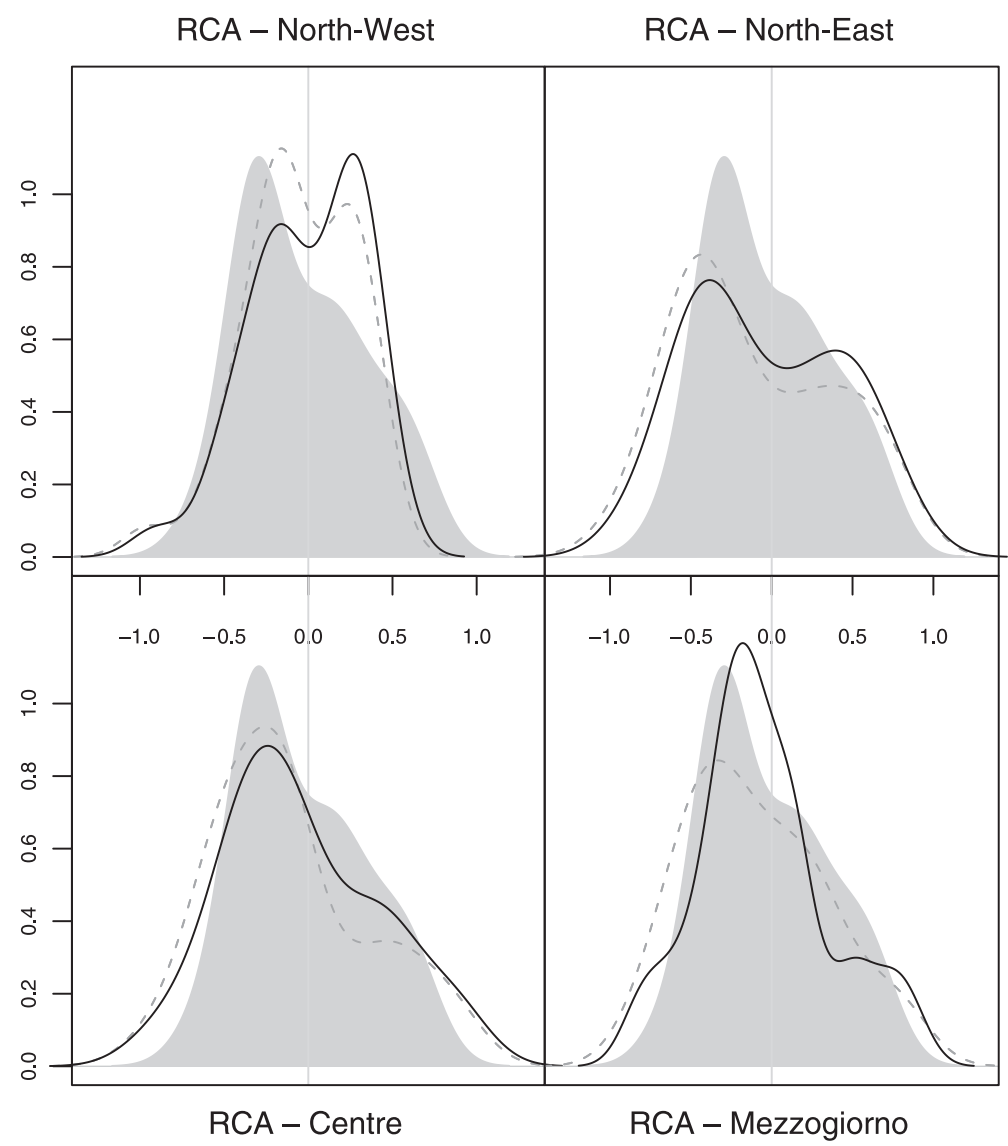

than the distribution of $b$ we opted again for a bounded version of the index, transforming $\Theta$ in $\Theta^{B}=\frac{(\Theta-1)}{\Theta+1}$, and Italian export data was applied at the provincial level collected by the National Institute of Statistics (ISTAT, 2002) between 1991 and 2001. (See the Appendix for a detailed description of the data set.)

\section{a. Regional RCA Densities}

The issue of national RCA being determined by specific regional overall specialisation is explored with the help of kernel densities, comparing the national estimated density function with the density functions of Italian regions, aggregated in four different macro-areas. 
The four macro-areas considered consist of provinces in the North-West, the North-East, the Centre, and the Mezzogiorno of Italy ${ }^{18}$ In each panel of Figure 5 the estimated distribution of the $\Theta^{B}$ values was plotted for each macro-area in 1991, the dotted line, and 2001, the continuous line, together with the estimated distribution of the $b^{B}$ values for Italy in 1991, the shaded area common to the four panels.

We can compare national and regional values in 1991, just to give evidence of the differences in overall specialisation, and also changes in regional densities along time can also be observed, as we did for national RCA in Figure 4. In all four cases regional distributions are different from the national one in some respects. (In all cases the two-sample Kolmogorov-Smirnov test did not accept the null hypothesis of the two distributions being drawn from the same continuous distribution.) The North-Western provinces are characterised by a more concentrated distribution (both in 1991 and in 2001), with an evident bimodality. From 1991 to 2001 the number of sectors with a positive $\Theta^{B}$ has increased, and the principal mode has moved from negative to positive. In North-Eastern and Centre provinces the shape of the density function did not change much, but the secondary mode had a rise in relevance. In the Mezzogiorno extreme $\Theta^{B}$ values converged towards the mode or diverged, moving towards the edges of the distribution, generating a noteworthy bilateral step in the density function. In all macro-areas the median of the $\Theta^{B}$ values moved to the right from 1991 to 2001 .

In summary, all macro-areas contributed to the switch to the right of the national density function observed in Figure 4, but the relative contribution of each area is quite different. The major changes are the ones observed in the North-Western provinces, where the principal mode is now substantially positive, and in the Mezzogiorno. The degree of persistence is also very different across macro-areas. Can this be related to the organisational structure of firms in the different provinces? Have industrial districts anything to do with the persistence of Italian RCA?

\section{b. Industrial Districts and Persistence}

In the first section of the paper we founded the explanation of the actual structure of Italian comparative advantages on the existence of learning-by-doing externalities associated with the presence of industrial districts. An empirical validation of that presumption is now sought. A direct test is, however, difficult to put forward, so an indirect test was chosen, asking if sectors and provinces

${ }^{18}$ The regions belonging to the four macro-areas are the following: Valle d'Aosta, Piemonte Lombardia and Liguria in the North-West; Veneto, Trentino Alto-Adige, Friuli Venezia-Giulia and Emilia Romagna in the North-East; Toscana, Marche, Umbria and Lazio in the Centre; and Abruzzo, Molise, Puglia, Campania, Basilicata, Calabria, Sicilia and Sardegna in the Mezzogiorno. 
characterised by the presence of industrial districts have a significative effect on the persistence of Italian RCA.

Theory does not offer a clear-cut prediction. On the one hand, the clustering of firms, allowing growth in productivity through a cooperative network of information-sharing and co-participation to innovation, promotes horizontal and vertical differentiation, granting firms producing labour-intensive goods to internationally compete with productions coming from labour-abundant NICs. The prevalence of cooperation over competition among firms in the cluster also allows follower firms to rapidly adapt to successful strategies adopted by the leading firm in the sector. Within-product flexibility and the ability to rapidly adapt to changes should therefore be enhanced in clustered firms. On the other hand, firms clustered in a district may be less sensible to market signals when lock-in phenomena are more pronounced; that would inhibit the propensity to change sectoral product specialisation, favouring RCA's persistence. The question should therefore be addressed empirically.

Fortunately, the long and fruitful tradition of studies on the role of the industrial districts in shaping the structure of the Italian economy ${ }^{19}$ has recently been enriched by the collection and elaboration of data by the Italian National Statistical Institute (ISTAT, 1997). We will make use of this data, ${ }^{20}$ jointly examining the export structure of the 104 Italian provinces and the presence of industrial districts in each province.

Unfortunately, the time span covered by the data only covers ten years, from 1991 to 2001, while the sectoral aggregation allows us to consider 35 manufacturing sectors of the SITC (rev. 2) classification (ISTAT, 2002). The data on industrial districts (ISTAT, 1997) identifies 616 local labour systems, that, excluding the food districts, reduces to 259 districts specialised in the production and export of Paper, Chemicals, Machinery, Miscellaneous Manufactured Articles (Toys, Musical Instruments and Jewellery), Leather and Footwear, Furniture, Nonmetallic Mineral Manufactures, Textiles, and Apparel and Clothing. Noteworthy, in some sectors where the scale of production is a relevant factor, the presence of industrial districts is null or very limited (Chemicals, Iron and Steel, Road Vehicles); the majority of the districts are concentrated in the traditional sectors (Leather, Textiles, Furniture, Apparel and Clothing, Footwear, Miscellaneous Manufactured Articles) and in sectors producing machineries (Power Generating Machinery, Specialised Machinery, Metal Working Machinery) and is localised in the North-East and Central Italian provinces; the number of districts in the

\footnotetext{
${ }^{19}$ See Becattini (1999) for a recent summing up and Signorini (2000) for a quantification of the district effect in firm's efficiency.

${ }^{20}$ We use the ISTAT (1997) classification since it is the most widely used. Many other classifications are, however, available (IPI, 2002). Every classification is prone to criticism and each classification tends to over- or under-estimate the phenomenon.
} 
Mezzogiorno is very limited. In our analysis we used a modified version of the ISTAT classification defined by Lucia Piscitello that allows us to consider not only the main sector of specialisation of the district but also the eventual second main sector. The resulting total number of sectoral districts amounts to 313 .

Several characteristics of the data on RCA in the Italian provinces must be taken into account: (a) $\Theta^{B}$ is a bounded index, a large number of observations have a $\Theta^{B} \approx-1$ (almost 30 per cent of the observations have values lower than -0.9 ), more than eight per cent of the observations have high $\Theta^{B}$ values (greater than 0.5); (b) the ISTAT-Piscitello classification allows us to construct a dichotomous variable associated with the presence or absence of industrial districts in a sector of a certain province, but does not allow to quantitatively differentiate (small vs big; mono-product vs multi-product; old vs new, homogeneous structure of firms vs pyramidal structure) one district from the other; (c) the number of provinces changed from 1991 to 2001; eight new provinces were instituted after 1995: this inflates the number of $\Theta^{B}=-1$ in the first years considered. ${ }^{21}$

Figure 6 describes the scatter plots of nine over the 35 sectors included in the original data set. Having the $1991 \Theta^{B}$ values on the horizontal axis and the $2001 \Theta^{B}$ values on the vertical axis, the spots identify the sectoral RCA of the 104 Italian provinces: the darker spots correspond to the provinces characterised by the presence of industrial districts, the empty spots to the provinces characterised by the absence of industrial districts, and the shaded square identifies the $b^{B}$ value for Italy, derived in expression (5). We also plotted in all panels a $45^{\circ}$ dotted line and the continuous OLS regression line.

Two things are worth noting: the remarkable presence of industrial districts in sectors of national comparative advantages, and the higher degree of persistence (lower dispersion around the $45^{\circ}$ line) in sectors characterised by both positive or negative $b^{B}$ and by the presence or the absence of industrial districts. Persistence seems to be a prevalent feature in the subsample of sectors highlighted in Figure 6.

We will further explore the issue through the following Galtonian regression: ${ }^{22}$

$$
\Theta_{j p 2001}^{B}=\alpha+\beta_{1} \cdot \Theta_{j p 1991}^{B}+\beta_{2} \cdot d_{j p}+\gamma \cdot \Theta_{j p 1991}^{B} \cdot d_{j p}+u_{j p},
$$

where $d_{j p}$ is a dichotomous variable that assumes value one if the sector $j$ in province $p$ is characterised by an industrial district, and zero otherwise, the interaction term permits different slopes for different levels of the factor $d_{j p}$, and

${ }^{21}$ This can be seen in Figure 6 where eight observations are systematically drawn in proximity to the vertical axis.

${ }^{22}$ A similar approach has been used in the analysis of RCA by Crafts and Thomas (1986), Amendola, Guerrieri and Padoan (1992) and Laursen (2002). 
FIGURE 6

A Selection of Sectors - Italian Provinces (1991-2001).
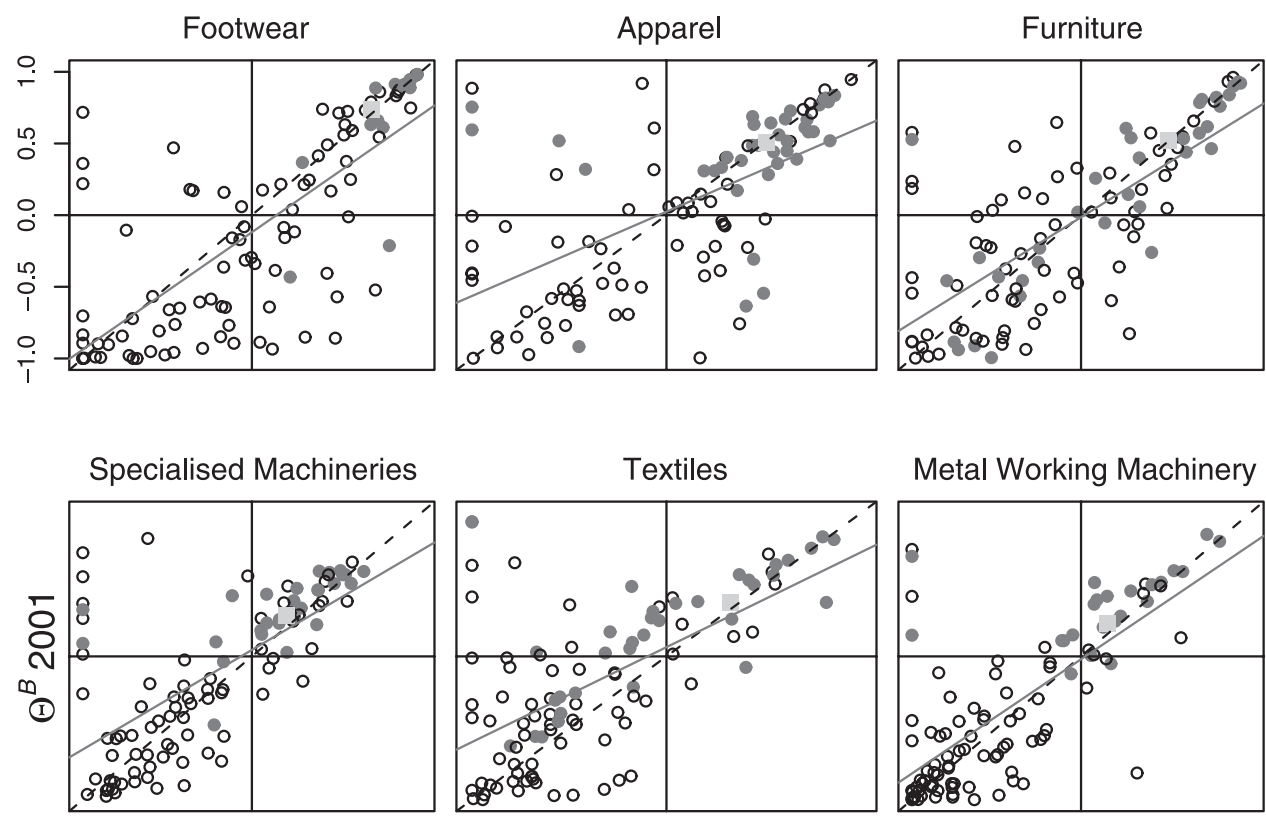

Metal Working Machinery
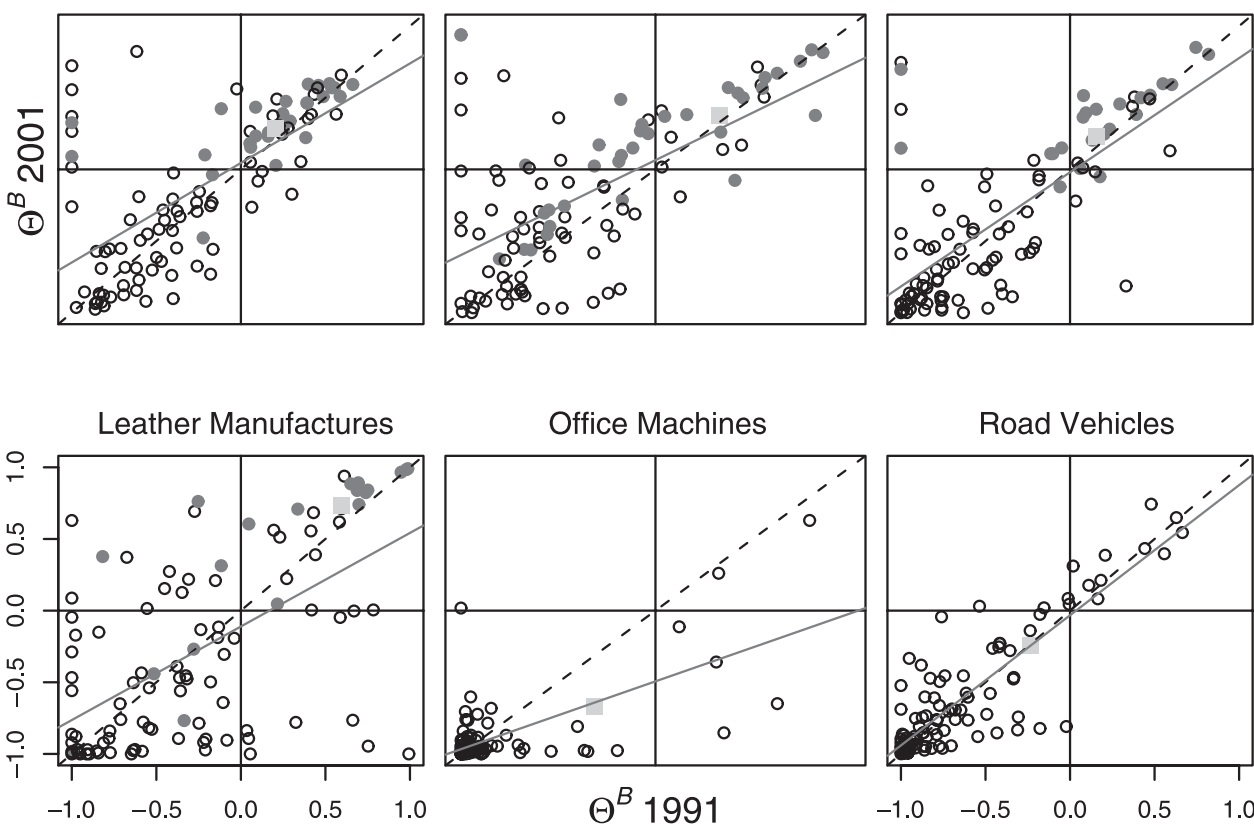

Note:

Dark spots identify provinces characterised by the presence of industrial districts (according to the ISTATPiscitello classification); the shaded square identifies the $b^{B}$ value for Italy.

Data Source: ISTAT (1997 and 2002).

$u_{j p}$ is an error term. Those provinces that did not exist in 1991 were excluded from the data.

Regression results are summarised in Table 3. In all regressions presented, the coefficients of particular interest are $\hat{\beta}_{1}$ and $\hat{\gamma}$.

The $\hat{\beta}_{1}$ coefficient in regression (1) in Table 3 indicates a degree of persistence not far from the one visualised in Figure 3. The regression is a pooled version of 
TABLE 3

Galtonian Regressions: The Dependent Variable is $\Theta_{2001}^{B}$

\begin{tabular}{|c|c|c|c|c|}
\hline & (1) & (2) & (3) & (4) \\
\hline Intercept & $\begin{array}{c}-0.061 * * * \\
(0.007)\end{array}$ & $\begin{array}{c}0.111^{*} \\
(0.066)\end{array}$ & $\begin{array}{c}0.120^{*} \\
(0.066)\end{array}$ & $\begin{array}{c}0.114 * \\
(0.065)\end{array}$ \\
\hline$\Theta_{1991}^{B}$ & $\begin{array}{l}0.810^{* * * *} \\
(0.011)\end{array}$ & $\begin{array}{l}0.752 * * * \\
(0.013)\end{array}$ & $\begin{array}{l}0.713^{* * * *} \\
(0.013)\end{array}$ & $\begin{array}{l}0.729 * * * \\
(0.014)\end{array}$ \\
\hline district & & & $\begin{array}{l}0.164 * * * \\
(0.024)\end{array}$ & $\begin{array}{l}0.161^{* * *} \\
(0.024)\end{array}$ \\
\hline$\Theta_{1991}^{B} *$ district & & & $\begin{array}{l}0.133 * * \\
(0.043)\end{array}$ & $\begin{array}{l}0.121 * * \\
(0.042)\end{array}$ \\
\hline Macro-regional dummy & No & Yes & Yes & Yes \\
\hline Sectoral dummy & No & Yes & Yes & Yes \\
\hline Observations & 3,359 & 3,359 & 3,359 & 3,196 (no zeros) \\
\hline$\sigma_{u}$ & 0.349 & 0.338 & 0.335 & 0.335 \\
\hline$R_{a d j}^{2}$ & 0.614 & 0.636 & 0.638 & 0.641 \\
\hline$F$ & $5,347 * * *$ & $151.5^{* * *}$ & $149.1 * * *$ & $140.4 * * *$ \\
\hline
\end{tabular}

Notes:

Standard errors in parentheses.

Significant tails: 0.000: ‘***’; 0.001: ‘**’; 0.01: ‘*’.

the separate regressions shown in Figure 6 , the $\hat{\beta}_{1}$ coefficient is high, positive and significant: a change of one unit in $\Theta_{1991}^{B}$ will tend to increase $\Theta_{2001}^{B}$ by 0.81 . In regression (2) we controlled for sectoral and regional heterogeneity in data adding sectoral and macro-regional dummies to the regression. The coefficient $\hat{\beta}_{1}$ is not much reduced, indicating that only a minimal part of persistence is due to compositional effects attributed to sectoral characteristics or to the specific geographic location of firms. The fit of the regression improves and the $F$-test indicates that the dummy variables are statistically significant. In regression (3) the district dummy variable was included in a way that allowed for different intercepts in the regression line. If we compare two provinces having the same value of $\Theta_{j p}^{B}$ in 1991 the estimated value $\Theta_{i p}^{B}$ in 2001 will always be 0.164 higher for the province characterised by a district in the $j$-sector: industrial districts enhance Italian RCA. In regression (3) an interaction term was also added, whose coefficient $\hat{\gamma}$ catches the effect of districts on persistence. The estimated coefficient is positive and significant indicating that persistence is higher for provinces with sectors where firms clustering is present: the regression line for such provinces is $0.284+0.846 \cdot \Theta_{j p}^{B}$; while in the case of no districts the regression line is $0.120+0.713 \cdot \Theta_{j p}^{B}$. Finally, in regression (4) we only considered provincial sectors exporting abroad, so to focus on $\Theta_{j p}^{B}>-1$. The results are not much different: the level of persistence is a little bit higher, $\hat{\beta}_{1}=0.729$ and the effect of districts on the intercept and the slope of the regression is reduced. The main message remains the same, however: in the time span considered the presence of industrial districts is positively related to the persistence of RCA in Italy. 


\section{CONCLUSIONS}

Italy is a trade puzzle: an industrialised country with a highly persistent specialisation in labour-intensive traditional goods is an anomaly in the world trading system. In this paper we have explored the structure of Italian exports, making use of the Balassa index of revealed comparative advantage (RCA), focusing on the export structure itself, on its change over time and on its degree of persistence. The analysis has been developed through non-parametric statistical techniques that allow us to estimate the empirical distribution of the Balassa index and to track its dynamic change during three decades, from the 1970s to the present. As theory suggested, we relate this change to the role of industrial districts, in order to show how the organisation of firms in the local structure of production promotes or bounds it.

In spite of the high persistence in the structure of RCA, several changes have recently occurred. We have given evidence to some of them: (a) the Italian structure of comparative advantages is not only characterised by 'traditional sectors' and the relevance of 'machineries' is substantially increasing; (b) on the other hand, the intensity of the $b^{B}$ values associated to 'traditional sectors' still remains very high compared to other OECD countries, so that the distribution of the $b^{B}$ 's is still more right-skewed than other industrialised countries; (c) a conspicuous number of sectors comparatively disadvantaged in 1985 are now becoming more comparatively advantaged; (d) the overall specialisation is moving to the right, the bimodality of the 1980s has been inverted in the 1990s, the main mode of the distribution is unique and is above 1 , and almost 50 per cent of the manufacturing sectors are now comparative advantaged; (e) those national changes are mainly generated by the changes occurring in the distribution of RCA in provinces located in the North-West, where the production of machineries is located, and in the Mezzogiorno, highly specialised in traditional sectors; (f) the presence of industrial districts is positively related to the degree of persistence of RCA.

After 30 years the Italian anomaly is still there. We will see in the next decades if the signs of change that we are now depicting are just a temporary turbulence or instead are the indicators of a more radical turn in the Italian pattern of comparative advantages.

\section{APPENDIX}

\section{Data Description}

The empirical strategy followed in this paper has been largely dependent on data availability. Since the ideal data set consisting of a panel of highly spatially and sectorally disaggregated data is unavailable, we have been therefore moving 
from one data set to the other when a specific question required the use of a specific level of data disaggregation.

More precisely, the new OECD Stan database (OECD, 2002) has been used when an international comparison was required and the sectoral disaggregation should be around 20-30 sectors in order to make the visual representation meaningful; the World Bank TradeCAN database has been used (UN-World Bank, 1999) when we required a higher level of sectoral disaggregation; and finally the Italian ISTAT data set (ISTAT, 2002) was used when a higher level of spatial disaggregation was required.

More detailed explanations on the data used are given below.

The STAN database. The data (used in Figure 2) is collected by the OECD (2002), at the two-digit level of the SITC (rev. 2) classification. It covers around 75 per cent of world trade.

The sectors considered in the two-digit OECD (2002) data set are: Food, Beverages, Tobacco, Textiles, Wearing Apparel, Leather \& Products, Footwear, Wood Products, Furniture \& Fixtures, Paper \& Products, Printing \& Publishing, Industrial Chemicals, Other Chemicals, Petroleum Refineries \& Products, Rubber Products, Plastic Products (n.e.c.), Pottery \& China, Glass, Non-metallic Products (n.e.c.), Iron \& Steel, Non-ferrous Metals, Metal Products, Nonelectrical Machinery, Electrical Machinery, Transport Equipment, Professional Goods, and Other Manufacturing.

Deriving $b$ we have used the total (and sectoral) export of OECD countries as $w$ variable(s); which - according to OECD (2002) - corresponds to more than 70 per cent of total world exports.

The UN-World Bank database. The UN-World Bank (2000) TradeCAN data come from the COMTRADE database, the official trade database of the United Nations Statistical Office. The time series starts in 1985 in some countries and in 1986 in others, and ends at 1998. There are 82 reporting countries and 193 countries of origin. According to the collectors, 'Trade-CAN incorporates well over 90 per cent of world trade'.

TradeCAN uses the SITC (revision 2) classification, at two-, three- and fourdigit levels of disaggregation. We used the two-digit level in Table 2 (63 groups), and the four-digit level in Figures 3 and 4, and in Table 2 as well (786 subgroups). We only used data on manufacturing sectors (540 at the four-digit level) including sectors with SITC code from 5 to 9. Food sectors (codes 0, 1, 2 and 4) were not included because of the difficulties in separating raw material from manufactures. Ten manufacturing sectors were excluded from the analysis since there was no data available for 1998. The total number of yearly observations in our analysis amounts to 530 .

The ISTAT database. The ISTAT (2002) database collects data on Italian exports at the provincial level. The data includes all 104 Italian provinces, and the time span is ten years, from 1991 and 2001. 
The 35 sectors considered in the analysis are: Organic Chemicals; Inorganic Chemicals; Dyeing and Tanning; Medicinal and Pharmaceutical Products; Essential Oils for Perfume; Fertilisers; Plastics in Primary Forms; Plastics in Nonprimary Forms; Other Chemical Materials; Leather; Rubber Manufactures; Wood (excluding furniture); Paper; Textile; Non-metallic Mineral Manufactures; Iron and Steel; Non-ferrous Metals; Manufactures of Metal; Power Generating Machinery; Specialised Machinery; Metal Working Machinery; Other Industrial Machinery and Parts; Office Machines; Telecommunication and Sound Recording Apparatus; Electrical Machinery; Road Vehicles; Other Transport Equipment; Prefabricated Buildings and Sanitary; Furniture; Travel Goods and Handbags; Apparel and Clothing; Footwear; Professional and Scientific Instruments; Photooptical Goods and Watches; Miscellaneous Manufactured Articles.

\section{b-Values: 1970 and 1998}

The numerical values of the $b$ 's for Italy, Spain, Japan, Germany, US and the UK derived from the OECD (2002) database for 1970 and 1998 are included in Table A1.

Some information can be extracted from simple manipulation of the data contained in Table A1. Using the $b$ 's in a cardinal way allows the possibility of demarcation and of sectoral and country ranking. In 1970, the share of Italian exports in the textiles sector was proportional to the world share to an order of magnitude of 1.42; and in 1970 the share of the Italian textiles sector with respect to the Italian professional goods sector (the relative contribution to total export) was $(1.42)(0.59)=0.84$ times greater than for the sum of the countries considered in the sample set; and, finally, that in 1970 the share of the Italian textiles sector was $(1.42)(0.91)=1.29$ times greater than the same share for Germany.

\section{Estimating Kernel Densities}

The easier way of describing kernel densities is to relate them to histograms. As in Bowman and Azzalini (1997) the histogram may be written as:

$$
\tilde{f}\left(b^{B}\right)=\sum_{j=1}^{n} I\left(b^{B}-\tilde{b}_{j}^{B} ; h\right),
$$

where $b_{j}^{B}$ is the data (with $\left.j=1, \ldots, n\right) ; \tilde{b}_{j}^{B}$ is the centre of the interval in which $b_{j}^{B}$ falls, and $I\left(b^{B}-\tilde{b}_{j}^{B} ; h\right)$ is the indicator function of the interval $[-h, h]$.

The Kernel estimator has the form:

$$
\hat{f}\left(b^{B}\right)=\frac{1}{n} \sum_{j=1}^{n} w\left(b^{B}-\hat{b}_{j}^{B} ; h\right)
$$


TABLE A1

Our Elaborations on OECD (2002): $b-1970,1998$

\begin{tabular}{|c|c|c|c|c|c|c|c|c|c|c|c|c|c|}
\hline \multirow[t]{2}{*}{ Code } & \multirow[t]{2}{*}{ Sector } & \multicolumn{2}{|l|}{ Italy } & \multicolumn{2}{|l|}{ Japan } & \multicolumn{2}{|l|}{$U S A$} & \multicolumn{2}{|l|}{$U K$} & \multicolumn{2}{|l|}{ Spain } & \multicolumn{2}{|c|}{ Germany } \\
\hline & & 1970 & 1998 & 1970 & 1998 & 1970 & 1998 & 1970 & 1998 & 1970 & 1998 & 1970 & 1998 \\
\hline 0 & Food & 0.49 & 0.76 & 0.41 & 0.07 & 1.03 & 0.93 & 0.39 & 0.68 & 3.04 & 1.41 & 0.37 & 0.73 \\
\hline 0 & Beverages & 1.20 & 1.25 & 0.03 & 0.04 & 0.08 & 0.40 & 2.94 & 2.02 & 3.86 & 1.68 & 0.25 & 0.45 \\
\hline 0 & Tobacco & 0.02 & 0.15 & 0.00 & 0.14 & 2.28 & 2.67 & 2.11 & 0.80 & 0.65 & 0.24 & 0.33 & 0.71 \\
\hline 1 & Textiles & 1.42 & 2.29 & 1.79 & 0.49 & 0.35 & 0.73 & 1.13 & 1.01 & 0.84 & 1.04 & 0.91 & 0.88 \\
\hline 1 & Wearing Apparel & 3.38 & 3.14 & 1.23 & 0.06 & 0.29 & 0.68 & 0.82 & 1.03 & 1.32 & 0.76 & 0.67 & 0.85 \\
\hline 1 & Leather Products & 2.16 & 4.88 & 0.69 & 0.12 & 0.44 & 0.47 & 1.44 & 0.76 & 2.90 & 2.17 & 0.94 & 0.59 \\
\hline 1 & Footwear & 7.41 & 5.53 & 0.37 & 0.02 & 0.06 & 0.23 & 0.66 & 0.61 & 8.38 & 3.54 & 0.40 & 0.44 \\
\hline 0 & Wood Products & 0.54 & 0.46 & 0.59 & 0.03 & 0.70 & 0.85 & 0.13 & 0.14 & 1.59 & 0.59 & 0.33 & 0.42 \\
\hline 1 & Furniture, Fixtures & 1.81 & 3.44 & 0.34 & 0.08 & 0.30 & 0.54 & 0.65 & 0.52 & 1.85 & 1.24 & 1.50 & 0.83 \\
\hline 0 & Paper Products & 0.27 & 0.57 & 0.22 & 0.17 & 0.92 & 0.95 & 0.33 & 0.54 & 0.29 & 0.70 & 0.32 & 0.88 \\
\hline 0 & Printing, Publishing & 1.13 & 0.94 & 0.51 & 0.16 & 1.20 & 1.26 & 1.54 & 1.97 & 3.95 & 1.30 & 0.93 & 1.07 \\
\hline 2 & Industrial Chemicals & 0.74 & 0.65 & 0.89 & 0.80 & 1.20 & 1.12 & 0.89 & 1.06 & 0.72 & 0.76 & 1.27 & 1.23 \\
\hline 2 & Other Chemicals & 0.78 & 0.73 & 0.34 & 0.64 & 1.15 & 0.94 & 1.52 & 1.53 & 0.60 & 0.70 & 1.17 & 1.08 \\
\hline 2 & Petroleum, Refineries, Products & 2.23 & 0.70 & 0.12 & 0.29 & 0.76 & 0.78 & 1.06 & 1.06 & 2.35 & 1.41 & 0.86 & 0.48 \\
\hline 0 & Rubber Products & 1.30 & 0.97 & 1.29 & 1.20 & 0.59 & 0.69 & 1.33 & 0.96 & 2.38 & 1.89 & 0.87 & 1.10 \\
\hline 0 & Plastic Products, n.e.c. & 2.10 & 1.67 & 1.90 & 0.28 & 0.62 & 0.87 & 0.75 & 0.90 & 0.67 & 1.03 & 1.03 & 1.11 \\
\hline 1 & Pottery, China etc. & 1.36 & 1.58 & 2.95 & 1.51 & 0.12 & 0.44 & 1.70 & 1.69 & 0.98 & 1.31 & 1.41 & 0.95 \\
\hline 1 & Glass Products & 1.25 & 1.13 & 0.61 & 0.85 & 0.80 & 0.82 & 0.84 & 0.61 & 0.74 & 1.15 & 1.07 & 1.00 \\
\hline 1 & Non-metallic Products, n.e.c. & 2.23 & 3.28 & 0.71 & 0.55 & 0.61 & 0.36 & 0.98 & 0.70 & 1.34 & 3.46 & 1.14 & 0.80 \\
\hline 0 & Iron Steel & 0.49 & 1.05 & 2.01 & 1.24 & 0.50 & 0.33 & 0.64 & 0.89 & 0.38 & 1.31 & 1.04 & 1.08 \\
\hline 0 & Non-ferrous Metals & 0.30 & 0.53 & 0.34 & 0.49 & 0.73 & 0.74 & 1.23 & 0.91 & 0.76 & 0.95 & 0.58 & 0.91 \\
\hline 0 & Metal Products & 1.16 & 1.70 & 1.08 & 0.71 & 0.78 & 0.85 & 1.22 & 0.82 & 1.23 & 1.09 & 1.33 & 1.22 \\
\hline 2 & Non-electrical Machinery & 1.32 & 1.16 & 0.61 & 1.34 & 1.44 & 1.21 & 1.17 & 1.10 & 0.57 & 0.49 & 1.36 & 1.09 \\
\hline 2 & Electrical Machinery & 0.83 & 0.63 & 1.89 & 1.75 & 1.01 & 1.21 & 0.91 & 1.04 & 0.50 & 0.60 & 1.09 & 0.91 \\
\hline 2 & Transport Equipment & 0.68 & 0.58 & 1.07 & 1.24 & 1.26 & 0.98 & 1.02 & 0.86 & 0.65 & 1.61 & 1.03 & 1.14 \\
\hline 2 & Professional Goods & 0.59 & 0.57 & 1.38 & 1.65 & 1.48 & 1.37 & 1.13 & 1.11 & 0.23 & 0.35 & 1.32 & 1.03 \\
\hline 0 & Other Manufacturing & 1.39 & 1.79 & 1.47 & 0.72 & 0.72 & 0.68 & 2.13 & 1.89 & 0.62 & 0.56 & 0.80 & 0.54 \\
\hline
\end{tabular}


where $w$ is a symmetric probability function with zero mean called the kernel function. The kernel function can take various forms; if a normal density function is chosen, then $h$ - which is called the smoothing parameter - is the standard deviation of the function.

The function $w$ has generally little effect on the shape of the distribution, while $h$ is crucial in determining the smoothness of the estimate. In the analysis we used a Gaussian kernel and an optimal $h$ (Bowman and Azzalini, 1997).

\section{REFERENCES}

Amendola, G., P. Guerrieri and P. C. Padoan (1992), 'International Patterns of Technological Accumulation and Trade', Journal of International and Comparative Economics, 1, 2, 173-97.

Amighini, A. and S. Chiarlone (2004), 'Cina', Rivista di Politica Economica, IX-X, 275-345.

Balassa, B. (1965), 'Trade Liberalisation and Revealed Comparative Advantage', Manchester School of Economics and Social Studies, 32, 2, 99-123.

Ballance, R. H., H. Forstner and T. Murray (1987), 'Consistency Tests of Alternative Measures of Comparative Advantage', Review of Economics and Statistics, LXIX, 1, 157-61.

Becattini, G. (1989), Modelli locali di sviluppo (Il Mulino, Bologna).

Becattini, G. (1999), Distretti industriali e made in Italy. Le basi socioculturali del nostro sviluppo (Boringhieri, Torino).

Bowen, H. P. (1983), 'On the Theoretical Interpretation of Indices of Trade Intensity and Revealed Comparative Advantage', Weltwirtschaftliches Archiv, 119, 3, 464-72.

Bowman, A. W. and A. Azzalini (1997), Applied Smoothing Techniques for Data Analysis (Clarendon Press, Oxford).

Brasili, A., P. Epifani and R. Helg (2000), 'On the Dynamics of Trade Paterns', De Economist, 148, 2, 233-58.

Brusco, S. and S. Paba (1997), 'Per una storia dei distretti industriali italiani dal secondo dopoguerra agli anni novanta', in F. Barca (ed.), Storia del capitalismo italiano dal dopoguerra ad oggi (Donzelli, Roma).

Burkart, M., F. Panunzi and A. Shleifer (2002), 'Family Firms', CEPR Discussion Paper No. 3234.

Conti, G. (1978), 'La posizione dell'Italia nella divisione internazionale del lavoro', in A. Piero (ed.), Specializzazione e competitività internazionale dell' Italia (il Mulino, Bologna).

Crafts, N. F. R. and M. Thomas (1986), 'Comparative Advantage in UK Manufacturing Trade, 1910-1935', Economic Journal, 96, September, 629-45.

De Benedictis, L. and P. C. Padoan (1999), 'Dynamic Scale Economies, Specialization, and the Cost of the Single Currency', International Journal of Development Planning Literature, 14, 4, 549-60.

De Benedictis, L. and M. Tamberi (2000), 'La specializzazione internazionale dell'Italia: anomalie, dinamica e persistenza', in Rapporto sull' industria italiana (Centro Studi Confindustria, Maggio).

De Benedictis, L. and M. Tamberi (2001), 'A Note on the Balassa Index of Revealed Comparative Advantages', SSRN Working Papers (http://ssrn.com/abstract=289602).

De Benedictis, L. and M. Tamberi (2004), 'Overall Specialization Empirics: Techniques and Applications', Open Economies Review, 15, 4, 323-46.

De Cecco (2004), 'Il declino della grande impresa', in I. Visco et al. (eds) Il declino economico dell' Italia. Cause e rimedi, Ch. 8 (Bruno Mondadori, Milano).

de Nardis, S. (1997), 'Fenomeni di persistenza e cambiamento nelle specializzazioni dei paesi industriali', Rivista di Politica Economica, 137, 1, 89-105.

de Nardis, S. and F. Traù (1999), 'Specializzazinone settoriale e qualità dei prodotti: misure della pressione competitiva sull'industria italiana', Rivista italiana degli economisti, IV, 2, 177-212. 
Epifani, P. (1999), 'Sulle determinanti del modello di specializzazione internazionale dell'Italia', Politica Economica, 15, 2, 195-224.

Faini, R. (2004), 'Fu vero declino? L'Italia negli anni '90', in I. Visco et al. (eds.), Il declino economico dell' Italia. Cause e rimedi, Ch. 3 (Bruno Mondadori, Milano).

Ginzborg, P. (1989), Storia dell'Italia dal dopoguerra a oggi (Einaudi, Torino).

Glamann, K. (1974), 'European Trade 1500-1750', in C. M. Cipolla (ed.), The Fontana Economic History of Europe: The Sixteenth and Seventeenth Centuries, Ch. 6 (Collins/Fontana, London), 427-526.

Graziani, A. (1989), L'economia italiana dal 1945 ad oggi (Il Mulino, Bologna).

Guerrieri, P. and S. Rossi (2000), 'Vantaggi competitivi reali nell'Europa con un solo mercato e una sola moneta', in P. C. Padoan (ed.), L'euro e i mercati reali, Ch. 1 (Il Mulino, Bologna).

Guiso, L., P. Sapienza and L. Zingales (2004), 'Does Local Financial Development Matter?', Quarterly Journal of Economics, 119, 3, 929-69.

Iapadre, L. (1996), 'La collocazione internazionale dell'economia italiana: indicatori statistici e tendenze recenti', Economia Italiana, 3, 437-83.

Iapadre, L. (2001), 'Measuring International Specialization', International Advances in Economic Research, 7, 2, 173-83.

IPI (2002), L'esperienza italiana dei distretti industriali, Istituto per la promozione industriale (Ministero delle attività produttive, Roma).

ISTAT (1997), I sistemi locali del lavoro 1991, F. Sforzi (ed.) (Istituto Poligrafico e Zecca dello Stato, Roma).

ISTAT (2002), 'Dati di commercio estero delle province italiane' (October).

Kim, S. (1995), 'Expansion of Markets and the Geographic Distribution of Economic Activities: The Trends in U.S. Regional Manufacturing Structure, 1960-1987', Quarterly Journal of Economics, 110, 4, 881-908.

Krugman, P. (1987), 'The Narrow Moving Band, the Dutch Disease, and the Competitive Consequences of Mrs. Thatcher: Notes on Trade in the Presence of Dynamic Scale Economies', Journal of Development Economics, 27, 41-55.

Lafay, J. (1992), 'The Measurement of Revealed Comparative Advantages', in M. G. Dagenais and P. A. Muet (eds.), International Trade Modelling (Chapman \& Hall, London), 209-34.

Laursen, K. (2002), Trade Specialization, Technology and Economic Growth (Routledge, London).

Lutz, V. (1962), Italy. A Study in Economic Development (Oxford University Press, Oxford).

Mancusi, M. L. (2001), 'Technological Specialization in Industrial Countries: Patterns and Dynamics', Weltwirtschaftliches Archiv, 137, 4, 593-621.

Modiano, P. (1982), 'Competitività e collocazione internazionale delle esportazioni italiane: il problema dei prodotti tradizionali', Economia e Politica Industriale, 33.

Nardozzi, G. (2004), Miracolo e declino (Laterza, Bari).

OECD (2001), Science, Technology and Industry Scoreboard. Benchmarking Knowledge-based Economies (OECD, Paris).

OECD (2002), STAN Database - 2002 edition (OECD, Paris).

OECD (2005), OECD Handbook on Economic Globalisation Indicators (OECD, Paris).

Onida, F. (1978), Industria italiana e commercio internazionale (Il Mulino, Bologna).

Onida, F. (1999), 'Quali prospettive per il modello di specializzazione internazionale dell'Italia', Economia Italiana, 3, 573-626.

Pagano, P. and F. Schivardi (2003), 'Firm Size Distribution and Growth', Scandinavian Journal of Economics, 105, 2, 255-74.

Peneder, M. (2003), 'Industry Classification: Aim, Scope, and Techniques', Journal of Industry, Competition and Trade, 3, 1/2, 109-29.

Rossi, N. and G. Toniolo (1996), 'Italy', in N. Crafts and G. Toniolo (eds.), Economic Growth in Europe since 1945 (Cambridge University Press, Cambridge).

Schott, P. K. (2004), 'Across-product versus Within-product Specialization in International Trade', Quarterly Journal of Economics, 119, 2, 647-78.

Signorini, L. F. (ed.) (2000), Lo sviluppo locale. Un'indagine della Banca d'Italia sui distretti industriali (Meridiana libri, Donzelli, Roma). 
Silverman, B. W. (1986), Density Estimation for Statistics and Data Analysis (Chapman \& Hall, London).

UN-World Bank (1999), TradeCAN Database (World Bank, Washington, DC).

Vollrath, T. L. (1991), 'A Theoretical Evaluation of Alternative Trade Intensity Measures of Revealed Comparative Advantage', Weltwirtschaftliches Archiv, 127, 2, 265-80.

World Bank (2004), World Development Indicators (World Bank, Washington, DC).

Yeats, A. J. (1985), 'On the Appropriate Interpretation of the Revealed Comparative Advantage Index: Implications of a Methodology Based on Industry Sector Analysis', Weltwirtschaftliches Archiv, 121, 1, 61-73.

Yi K.-M. (2003), 'Can Vertical Specialization Explain the Growth of World Trade?', Journal of Political Economy, 111, 1, 52-102. 